\section{Building resilient and responsive health systems for geriatric care in India}

\author{
Sandul Yasobant, ${ }^{1}$ Kranti Vora, ${ }^{2}$ \\ Deepak Saxena ${ }^{2}$
}

${ }^{1}$ Center for Development Research (ZEF), University of Bonn, Germany; ${ }^{2}$ Indian Instititue of Public Health, Gandhinagar, India

\section{Dear Editor,}

Currently, more than $12 \%$ of the world's elderly population lives in India. The demographic trends suggest that between the years 2000-2050, the Indian population in their 60 s and above will increase by $326 \%$, while those in the age group of $80+$ will increase by $700 \%$ - the fastest growing group. ${ }^{1}$ With this demographic transition, very soon India might become a grey nation. As a consequence, the proportion of disease burden contributed by cancers, cardiovascular conditions, diabetes, musculoskeletal disorders and neurological disorders such as dementia, hearing and vision loss, is expected to increase. ${ }^{2}$ Therefore, we aimed to do a situational analysis and identify opportunities to build resilient health system for better geriatric care in India.

\section{Overview of the Indian health system}

Indian health system is presently struggling with rapidly changing demographics and disease burden. Underfinancing, shortage of skilled human resource for health are one of the greatest challenges to respond to changing priorities. ${ }^{3}$ Currently, we are passing through a stage of epidemiological mosaic with an unfinished agenda of infectious diseases and maternal, child health problems with an added burden of Noncommunicable diseases due to aging population. Indian health system has responded to these changes, but in addition to limited public health infrastructure there are also issues such as geographical vastness, sociocultural diversity and rural-urban differences throughout the nation. ${ }^{4}$

In addition to infrastructure issues dogging public sector there is a vast private sector in India that caters to more than two thirds of health services. A mixed health care market of public and private providers is a reality as India is an under-resourced country with respect to human resources for health. ${ }^{5}$ Because of limited access in public sector, formal and informal private providers remain the main source for primary health care services in India. ${ }^{6}$

\section{Current geriatric care system in India}

Geriatrics health care in India is in its nascent stage. Indian Government has focused on rural healthcare since independence and developed a three tier healthcare delivery system to improve access in remote areas by providing primary care at the village level, secondary care at the subdistrict and district levels, and tertiary care at the regional level. Medical colleges are developed as apex institutes with specialties. Neither infrastructure wise nor by skilled training of human resources, these three tier system healthcare services are geared for geriatrics care except in few apex institutes. To improve public sector capacity for health services targeted for elderly, the Govt. of India has implemented a national level health program called National Programme for the Health Care for the Elderly (NPHCE) in 2011. ${ }^{7}$ NPHCE program focused on development of Regional Geriatric Centers (RGC), specific geriatric ward, training of health personnel in geriatric healthcare and conducting research including Postgraduate degree in geriatric medicine in the $\mathrm{RGCs}^{8}$

\section{Opportunities to build a resilient geriatric care system in India}

Currently, Indian health system has a mixed market and there are ample opportunities if private providers are included into the current strategies of planning for universal health care. Unfortunately, for the geriatrics care in reference to NPHCE, there is no concept of public-private mix. We propose that public-private mix could be a potential strategy to improve access to geriatric care with available resources and it could lead to building a responsive health system. We use relevant resilient health system criteria ${ }^{9}$ to propose strategies to build the same for geriatric care in India.

First, systems awareness: developing an up-to-date map of resources available including private sector and not limiting to RGCs. Mapping would help identify resource gaps in human, physical, and information and help in efficient planning and monitoring.

Second, system diversity: geriatric care services should address a broad range of health services needs starting from curative to preventive services in a comprehensive package for each tier.

Third, systems integration: geriatric care should be integrated with allied sectors like old-age homes, education department etc. As geriatric care requires multidisciplinary
Correspondence: Sandul Yasobant, Center for Development Research (ZEF), Walter Flex Str.3, 53113 Bonn, Germany.

Tel: +49-162-161-0570.

Email: dryasobant@gmail.com

Key words: Resilient health systems; Responsive health systems; Geriatric care; India.

Contributions: SY, KV, DS equally contributed to the manuscript.

Conflict of interest: the authors declare no potential conflict of interest.

Received for publication: 13 April 2016 Revision received: 28 February 2017.

Accepted for publication: 17 March 2017.

This work is licensed under a Creative Commons Attribution 4.0 License (by-nc 4.0).

CCopyright S. Yasobant et al., 2017

Licensee PAGEPress, Italy

Healthcare in Low-resource Settings 2017; 5:5932 doi:10.4081/hls.2017.5932

team, integration with other sectors is vital for holistic and culturally appropriate care.

Fourth, system adaptation: as the current system does not have geriatric care as a focus area, once that has been achieved, system should be able to adapt to any shocks.

Health system resilience has been well understood only after the Ebola out-break, ${ }^{10}$ similarly it is important to build such system for geriatric care in India. Improved system would be able to withstand any upcoming challenges. In the current health system scenario of India and given the magnitude of the service provision in this country of billions, it is important to take baby steps towards building responsive and resilient system for the elderly. It seems a daunting task but Indian health system has adapted in the past and can continue to do so in its endeavor to provide universal health care.

\section{References}

1. Verma R, Khanna P. National program of health-care for the elderly in India: a hope for healthy ageing. Int J Prev Med 2013;4:1103-7.

2. Thakur R, Banerjee A, Nikumb V. Health problems among the elderly: a cross-sectional study. Ann Med Health Sci Res 2013;3:19-25.

3. Kumar JR. Role of public health systems in the present health scenario: key challenges. Indian J Publ Health 2013;57:133-7. 
4. Engelgau MM, El-Saharty S, Kudesia P, et al. Capitalizing on the demographic transition: tackling noncommunicable diseases in South Asia. Washington, DC: World Bank; 2011.

5. Srinivisan R. Health care in Indiavision 2020: issues \& prospects. New Delhi, India: Government of India, Planning Commission of India; 2010.

6. Alok M. Public-private partnership in the health sector in India. Public-Private Partnerships. 2000. Available from: uhrc.in/uhgateway/documents/1073.pdf

7. Indian Ministry of Health and Family Welfare. National Programme for the Health Care of the Elderly (NPHCE): An approach towards active and healthy ageing. New Dehli: Directorate General of Health Services, Ministry of Health and Family Welfare, Government of India; 2011.

8. Indian Ministry of Health and Family Welfare. National Programme for the Health Care of the Elderly. Operational
Guidelines. New Dehli: Ministry of Health and Family Welfare, Governement India; 2011.

9. Maresso A, Wismar M, Greer S, Palm W. What makes healthsystems resilient \& innovative? Voices from Europe. Eurohealth Obs 2013;19:3-6.

10. Kruk ME, Myers M, Varpilah ST, Dahn BT. What is a resilient health system? Lessons from Ebola. Lancet 2015;385:1910-2. 